\title{
Detection of Microcalcifications in Women with Dense Breasts and Hypoechoic Focal Lesions: Comparison of Mammography and Ultrasound
}

\author{
In-vivo-Nachweis von Mikrokalk
}

Authors

Affiliations
M. Grigoryev ${ }^{4^{*}}$, A. Thomas ${ }^{1 *}$, L. Plath ${ }^{4}$, T. Durmus ${ }^{4}$, T. Slowinski ${ }^{2}$, F. Diekmann ${ }^{3}$, T. Fischer ${ }^{4}$

Department of Obstetrics and Gynecology and Ultrasound Research Laboratory, University Berlin, Charité, Berlin

Institute of Nephrology, University Berlin, Charité, Berlin

Institute of Radiology, St. Joseph-Stift, Bremen

Institute of Radiology and Ultrasound Research Laboratory, University of Berlin, Charité, Berlin

\author{
Key words \\ - microcalcifications \\ - detection of \\ microcalcifications \\ - breast ultrasound \\ - mammography \\ - MicroPure
}

received $\quad 1.6 .2013$

accepted 2.4.2014

Bibliography

DOI http://dx.doi.org/

10.1055/s-0034-1366466

Published online: May 28, 2014

Ultraschall in Med 2014; 35 :

554-560 @ Georg Thieme

Verlag KG Stuttgart · New York .

ISSN 0172-4614

\section{Correspondence}

\section{Prof. Dr. Anke Thomas}

Department of Obstetrics and Gynecology and Ultrasound

Research Laboratory, University Berlin, Charité

Charitéplatz 1

10117 Berlin

Germany

Tel.: ++ 49/30/450664564

Fax: ++49/30/450527957

anke.thomas@charite.de

\section{Abstract \\ $\nabla$}

Purpose: Microcalcifications in the breasts can point to breast cancer. However, there is great morphologic variety, and microcalcifications do not always correlate with malignancy. We conducted a prospective study to compare ultrasound and mammography in the detection of microcalcifications following sonographic diagnosis of a hypoechoic focal lesion in women with dense breast composition.

Materials and Methods: A total of 104 lesions potentially associated with microcalcifications (82 malignant and 23 benign lesions) were included in the study. The breast was examined by ultrasound ( $9 \mathrm{MHz}$, Aplio XG/500) with additional use of MicroPure imaging for the demonstration and evaluation of microcalcifications. The presence of a focal lesion was verified and microcalcifications were counted at ultrasound and mammography by blinded readers. The sensitivity and specificity were determined, and ROC analysis and AUC analysis were performed.

Results: The women had a median age of 51 years. The average number of microcalcifications detected by sonography $(2.12 \pm 2.77)$ and mammography $(3.59 \pm 6.35)$ was not significantly different $(p>0.05)$. Correlation of the techniques was adequate (Pearson's $r=0.616, p<0.0001$; Spearman's rho $=0.654, \mathrm{p}<0.0001)$. The intraclass correlation coefficient was $\mathrm{K}=0.382 \pm 0.072(\mathrm{p}<0.0001)$, also indicating adequate agreement of both techniques. The sensitivity and specificity were $70 \%$ / $30 \%$ for MicroPure and $45 \% / 55 \%$ for mammography. The positive predictive value of mammography was superior to that of MicroPure ( $88 \%$ vs. $78 \%)$.

Conclusion: The sonographic detection of microcalcifications with MicroPure imaging in breasts with a hypoechoic focal lesion correlates well with digital mammography.

\section{Zusammenfassung \\ $\nabla$}

Ziel: Der Nachweis von Mikrokalk kann mit einem Mammakarzinom assoziiert sein, durch seine breite morphologische Vielfalt korreliert er nur teilweise mit der Dignität der zugrunde liegenden Gewebsveränderung. Ziel der prospektiven Studie war die Vergleichbarkeit von Mikroverkalkungen nach sonografischer Detektion eines echoarmen Herdbefundes mit der Mammografie im dichten Drüsengewebe.

Material und Methoden: 104 Herde mit potentiellen Mikroverkalkungen ( 82 maligne und 23 benigne Läsionen) wurden in die Studie eingeschlossen. Neben der sonografischen Untersuchung ( $9 \mathrm{MHz}$, Aplio XG/500) der Mammaläsion, erfolgte die Mikrokalkdarstellung mittels MicroPure Ultraschallverfahren. Das Vorhandensein einer fokalen Läsion wurde bestimmt und die Mikroverkalkungen wurden für jede Läsion sonografisch und mammografisch ausgezählt und von geblindeten Readern analysiert. Sensitivität, Spezifität, ROCAnalyse und die AUC-Analyse konnten statistisch ausgewertet werden.

Ergebnisse: Das mediane Alter betrug 51 Jahre. Die Zahl der sonografisch $(2,12 \pm 2,77)$ und mammografisch $(3,59 \pm 6,35)$ erkannten Mikroverkalkungen unterschied sich nicht signifikant $(p>0,05)$. Die berechneten Korrelationen der Verfahren waren ausreichend gut (Pearson's $r=0,616$, $\mathrm{p}<0,0001$, Spearman's rho $=0,654, \mathrm{p}<0,0001)$. Der Intraklassen-Korrelationskoeffizient war $\mathrm{K}=$ $0,382 \pm 0,072 \mathrm{p}<0,0001$ und zeigte eine ausreichend gute Übereinstimmung beider Verfahren. Sensitivität und Spezifität waren $70 \% / 30 \%$ für MicroPure und 45\%/55\% für die Mammografie. In der positiven Vorhersagekraft ist die Mammografie der MicroPure überlegen ( $88 \%$ vs. $78 \%$ ).

Schlussfolgerung: Sonografische Erkennbarkeit von Mikroverkalkungen mit MicroPure, beim Vorliegen eines echoarmen Herdbefundes, korreliert gut mit der digitalen Mammografie. 


\section{Introduction}

\section{$\nabla$}

Microcalcifications are common in invasive ductal carcinoma of the breast and its precursors $[1,2]$. The presence of microcalcifications is considered the first sign of malignancy in approx. $40 \%$ of women with nonpalpable breast cancer [1].

In an earlier ex vivo study, our group has shown that the sonographic technique of easier microcalcification detection (EMD; from which the MicroPure ultrasound imaging technique has been developed) allows good visualization of microcalcifications [3]. Can this performance be translated to the routine clinical setting [4]? Advances have been made in the sonographic detection of microcalcifications in recent years [5, 6] after Kasumi first reported the feasibility of sonographic detection of microcalcifications above a size threshold of $110 \mu \mathrm{m}$ as early as 1988 [7]. Nevertheless, reliable sonographic identification of microcalcifications continues to be difficult, especially in dense breasts. This difficulty is attributable to the fact that collagen fibers, just like microcalcifications, are seen as bright foci [8]. Hyperechoic microcalcifications are easier to detect against an anechoic background $[7,9,10]$. For this reason, any bright focus within an anechoic focal lesion is classified as suspicious in the ACR-BI-RADSUS Lexicon [11].

There is no agreement about the sensitivity and specificity of ultrasound for microcalcification detection [12 - 16]. Some authors have reported $95 \%$ sensitivity for the sonographic detection of microcalcifications $[7,15]$, while others consider ultrasound unsuitable for this purpose [12].

Despite good correlation between breast ultrasound and mammography, mammography continues to be superior to ultrasound and remains the gold standard for detecting microcalcifications $[3,16]$.

Following Mostbeck's editorial in the August 2012 issue of this journal, we addressed the question whether better sonographic detection of microcalcifications could improve cancer detection in mammographically dense breasts [4]. The current S3 guideline for breast cancer management recommends an ultrasound examination in women with dense breasts (ACR density index of III-IV) [17]. Dense breasts markedly degrade the visualization of focal lesions; and many studies have shown mammography supplemented by targeted ultrasound of suspicious areas to be superior to mammography alone [12, 17-20]. Mammography may miss small cancers in dense breasts. Breast ultrasound is an adjunct to mammograpy, particularly for further characterization of unclear microcalcifications. With an improved sonographic detection of microcalcifications, ultrasound could be used for biopsy guidance for target sampling of tissue containing microcalcifications. Ultrasound-guided breast biopsy is less expensive and does not involve radiation exposure, and it is more comfortable for the patient compared with stereotactic sampling as it does not require compression of the breasts.

Initial results with the MicroPure EMD technique, both in vivo and ex vivo, have shown that it improves the detection of microcalcifications [3].

The aim of our prospective in-vivo study was to compare the sonographic detection of microcalcifications in women with BIRADS category IV focal lesions with mammography in women with a dense breast composition (ACR III-IV).

\section{Material and Methods \\ $\nabla$}

The women presenting to the special consultation service of our breast center, certified according to the criteria of the German Cancer Society and the German Society of Senology, include women who are referred for further workup of suspicious focal breast lesions. In the period from Jan. 2010 through July 2012, 212 women with sonographically suspected focal breast lesions were seen at the breast center. A total of 104 of these women with 105 focal lesions were included in our prospective study. The other 108 cases were not included because a focal breast lesion was not confirmed or no mammogram was obtained because of age or refusal to participate in the study. One patient underwent bilateral breast biopsy on the same day, and both lesions were included in the study. Inclusion criteria were sonographically suspected microcalcifications in women with a prior diagnosis of a BI-RADS category IV hypoechoic focal lesion based on an external examination or an examination performed at the breast center. All patients gave written informed consent. Histology was available for all 105 lesions based on ultrasound-guided core biopsy.

\section{Ultrasound Examination}

All women were examined using a high-end ultrasound system (Aplio XG, Aplio 500 Toshiba Medical Systems, Otawara, Japan) with a 9-MHz linear broad-band transducer (805 BT, Toshiba, Otawara, Japan). B-mode scan quality was optimized by using techniques for improving lateral and axial resolution and reducing speckle noise (spatial and frequency compounding (FC) and differential Tissue Harmonic Imaging (THI)). For easier microcalcification detection in the dual mode, a software tool implemented on the system platform was used (MicroPure Toshiba, Otawara, Japan). With MicroPure, different levels of sensitivity, corresponding to different color maps, can be selected (level 0 2 , blue; level 3-5, violet; level 6-8, black and white). Earlier investigations of our group found levels 1 and 2 to be most sensitive to microcalcifications and least susceptible to artifacts [17]. For details of FC and the technique of EMD (MicroPure), the reader is referred to Thomas et al. 2007 [3], Fischer et al. 2012 [17], and Machado et al. 2012 [14].

The sonographic examinations were performed according to a standardized protocol. The first step was to document the target lesion on a B-mode image showing the largest extent of the lesion. Next, two B-mode images showing the lesion in two planes (sagittal and axial) were displayed on the monitor in the split screen mode along with a level 1 MicroPure images on the right side. Finally, the lesion and intralesional microcalcifications were documented in a real-time digital video clip. These raw datasets were digitally stored on the system's hard disc in the DICOM format; the examination was again conducted in axial and sagittal planes, and the video was documented.

The sonographic breast examinations were performed by a qualified examiner (TF) certified by the Deutsche Gesellschaft für Ultraschall in der Medizin (DEGUM, German Society for Ultrasound in Medicine) with level 3 training in radiology and level 2 in breast ultrasound. All patients included in the analysis underwent ultrasound-guided biopsy of the target lesion using a 14-G core biopsy needle. Two or three representative tissue samples were obtained with documentation of needle positions in two planes. When calcifications were demonstrated by ultrasound, tissue sampling was performed using the MicroPure technique for guidance. 


\section{Mammography}

All mammograms were obtained in two planes: mediolateral oblique (MLO) and craniocaudal (CC). Additional planes were used as deemed necessary by the physician performing the examination.

All mammograms were available digitally. Approx. $70 \%$ of the mammograms used in the present analysis were acquired in our department (on a MAMMOMAT Inspiration, Siemens AG, Munich, Germany). The remaining mammography examinations were performed by specialized practices or by mammography screening units (digital mammograms). When a patient was referred to the breast center, external mammogram data in DICOM format were digitized and transferred to our imaging archive. Breast density was automatically determined from the mammograms assigning one of four ACR density categories. (ACR density index of I-II = low density, ACR density index of III-IV = high density).

\section{Image Analysis}

A total of 420 individual images and 105 video clips were stored on the hard disc of the ultrasound system. First, the reader compared the lesion in the axial and sagittal planes on B-mode images and level 1 MicroPure images to assess microcalcifications and to identify artifacts. To differentiate between microcalcifications and artifacts, the angle of interrogation must be changed during the examination. For this reason, the digital video clips were used for identifying and counting microcalcifications. In our experience, static images do not allow differentiation between microcalcifications in the vicinity of focal lesions and artifacts (e.g., fibroglandular structures or Cooper's ligaments). Therefore, B-mode images were used to identify these structures and to differentiate between artifacts and true microcalcifications, which are not continuous and still appear as tiny dots when the transducer is rotated.

\section{Histology}

A total of 105 target lesions were histologically verified. Histology was performed immediately after storage of the sonographic datasets. Hematoxylin and eosin (H\&E) staining and the usual immunohistochemical stains were performed in a standardized fashion. For pathologic workup, the tissue cores containing microcalcifications were specifically labeled. The reference pathologist assessed these specimens for the presence of microcalcifications using standard H\&E stains. When surgical specimens were available, these were also evaluated for the presence of microcalcifications.

In five cases, specimen radiography was performed and demonstrated microcalcifications, which were later confirmed by histology. In all patients with malignant breast lesions, the final histologic diagnosis was also used for the analysis of microcalcifications.

\section{Analysis and Statistics}

In a first step, a skilled reader with DEGUM level III certification (AT) verified the presence of the lesion on the $105 \mathrm{~B}$-mode images displaying the maximum lesion extent. Next, the reader reviewed the axial and sagittal level 1 MicroPure images for the presence of microcalcifications within and around the lesions. In a further step, the microcalcifications were counted in all $105 \mathrm{vi}-$ deo clips. Calcifications were counted within the lesions and around the lesions (in an area with twice the lesion diameter). The video clips were analyzed in craniocaudal and mediolateral directions. For each target lesion, in both sonographic and mammographic analysis, a maximum number of 0 to 10 microcalcifications was defined. This was done, because sonographically, a further discrimination of very small, closely spaced microcalcifications $(<110 \mu \mathrm{m})$ is technically not possible and only the change in impedance is seen as a line. Mammographically, clusters of up to 30 individual calcifications were identified in some cases.

Mammograms were analyzed by a qualified physician (FD) to assess presence of a lesion, microcalcifications, number of microcalcifications within the lesion and in the periphery, and morphology of calcifications. If no lesion, architectural distortion, or density was apparent $(n=22)$, the reader was informed about the side and quadrant from which the biopsy had been obtained and then scrutinize this area again for the presence of microcalcifications.

In this way, microcalcifications were analyzed both sonographically and mammographically for all lesions included in the study. Agreement of microcalcification detection between mammography and ultrasound was assessed by Pearson regression analysis and Spearman rank correlation. In addition, interrater correlation coefficients (ICC, two-way random effects model, with both random person and random measure effects; type A intraclass correlation coefficients using a definition of absolute agreement) were calculated, and Bland-Altman plots were generated. Because mammography generally detects more calcifications than ultrasound, for calculation of correlations, the number was set to 10 in all cases where more than 10 microcalcifications were detected on mammograms. Histology was available as the gold standard. Therefore, $2 \times 2$ tables could be generated to compute the specificity, sensitivity, and positive predictive value of mammography and sonography for microcalcification detection. The predictive power of mammography and sonography for the histologic result was assessed by Receiver Operating Curve (ROC) with calculation of the Area under the Curve (AUC) for both modalities. Kappa statistics were used to assess and compare the detection of microcalcifications with ultrasound and mammography using histology as the gold standard. Statistical analysis was performed using two software packages, PASW Statistics, version 18.0 (SPSS Inc, Chicago, USA) and GraphPad Prism, version 5.0 (GraphPad Software, San Diego California, USA).

\section{Results \\ $\nabla$}

A total of 420 individual images (4 per patient: B-mode and level 1 MicroPure images, each in sagittal and axial planes) and 210 video clips of the target lesions were analyzed.

The women had a median age of 51 years. There was a higher proportion of women with dense breasts (65\% with ACR density categories $\geq 3$ ). Histology based on biopsies obtained with ultrasound guidance revealed 82 malignant and 23 benign lesions. The histologic diagnoses of all 105 lesions are summarized in - Table 1. The sonographic lesion size was $18.3 \pm 9.9 \mathrm{~mm}$.

Microcalcifications were counted on axial and sagittal B-mode images and on level 1 MicroPure images. In addition, the videos were analyzed, also in two planes, to differentiate microcalcifications from artifacts, predominantly caused by collagen fibers and Cooper's ligaments. Differentiation between these artifacts and true microcalcifications is easier using the video clips.

On mammograms, focal lesions were identified in 82 patients (79\%). Sonographically, focal lesions were identified in all 105 cases. In those case, where no lesion was identified on the mam- 
Table 1 Histologic diagnosis of benign and malignant breast lesions in the study population.

\begin{tabular}{|lllc|}
\hline $\begin{array}{l}\text { benign lesions } \\
\text { fibrocystic } \\
\text { mastopathy }\end{array}$ & $\mathbf{n = 2 3}$ & malignant lesions & $\mathbf{n = 8 2}$ \\
\hline fibroadenoma & 6 & invasive ductal carcinoma & 65 \\
\hline sclerosing fibrosis & 3 & invasive lobular carcinoma & 11 \\
\hline papilloma & 2 & & 3 \\
\hline phylloid tumor & 1 & ductal carcinoma in situ & 3 \\
\hline hamartoma & 1 & & \\
\hline radial scar & 1 & & \\
\hline PASH & & & \\
\hline Pseudoangiomatous stroma hyperplasia & \\
\hline
\end{tabular}
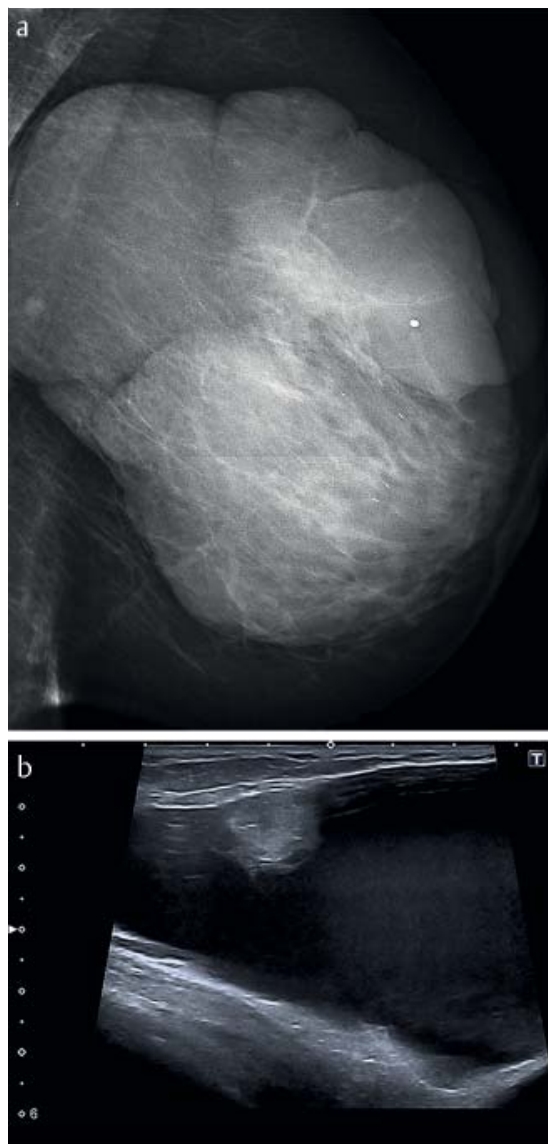

Fig. 1 This figure presents the procedure of image interpretation. The digital mammogram (L-CC image) shows a large, lobulated lesion with sharp margins. The lesion contains some very tiny, linear microcalcifications and a macrocalcification a. The corresponding B-mode ultrasound scan shows a large cyst with a solid formation contiguous with the cyst wall b. MicroPure reveals five microcalcifications within the lesion (histologically proven intracystic cancer with microcalcifications) $c$.

Abb. 1 Beschreibt den prinzipiellen Ablauf der Befundung. In der digitalen Mammografie (L-CC-Aufnahme) ist eine große, scharf begrenzte lobulierte Läsion mit einzelnen feinen linearen Mikro-

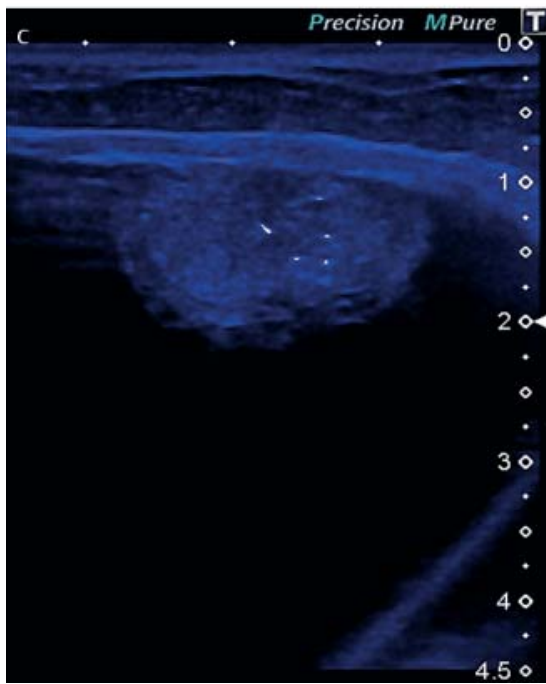

Table 2 Table for comparison of microcalcification detection by ultrasound and mammography.

\begin{tabular}{|lll|}
\hline & MicroPure ultrasound & mammography \\
\hline sensitivity & $70 \%$ & $45 \%$ \\
\hline $\begin{array}{l}\text { specificity } \\
\begin{array}{l}\text { positive predictive } \\
\text { value }\end{array}\end{array}$ & $30 \%$ & $55 \%$ \\
$\begin{array}{l}\text { negative predictive } \\
\text { value }\end{array}$ & $22 \%$ & $88 \%$ \\
\hline
\end{tabular}

mograms, the reader was informed about the sonographic lesion localization and then reassessed this area for microcalcifications. Overall, microcalcifications were reported for 73 lesions on ultrasound and 42 lesions on mammography. In 40 cases, microcalcifications were detected with both modalities ( $\bullet$ Fig. 1a-c).

The mean number of microcalcifications detected was $2.12 \pm 2.77$ for sonography and $3.59 \pm 6.35$ for mammography. The difference was statistically not significant ( $p>0.05$ ), ( $\bullet$ Fig. $2 a-b)$.

Correlation of mammography and ultrasound was good to adequate (Pearson's $\mathrm{r}=0.616, \mathrm{p}<0.0001$, Spearman's $\mathrm{rho}=0.654$, $\mathrm{p}<0.0001)$. Agreement of both modalities in terms of intraclass correlation coefficients was adequate $(K=0.382 \pm 0.072 \mathrm{p}<0.0001)$. Mammography was far superior to ultrasound in detecting clusters of very fine calcifications with over 10 discrete microcalcifications. For very small microcalcifcations $(<100 \mu \mathrm{m})$, the difference in impedance is too small to be detected as a discrete bright point ( $\mathbf{F i g}$. $3 a-c)$ ). Problems also occurred when a lesion contained both microcalcifications and macrocalcifications $(>0.5 \mathrm{~mm})$. In such cases, filtering in ultrasound results in comparable twingling signals despite the marked size differences.

As a consequence, ultrasound was limited in discriminating all microcalcifications when more than 10 were present within a lesion. This is illustrated by the Bland-Altman plot, which suggests good agreement of both modalities for lesions containing 0 to 10 microcalcifications ( $\mathbf{F i g . 4}$ ). The bias was $0.43 \pm 2.9$ (95\% limits of agreement from -5.3 to 6.2 ).

For comparison of mammography and ultrasound in terms of sensitivity and specificity, AUC analysis was performed after histologic examination. Mammography was found to be superior to ultrasound in microcalcifcation detection (AUC $=0.617$, lower limit 0.493, upper limit 0.741 versus $A U C=0.549$, lower limit 0.418, upper limit 0.680) ( $\odot$ Fig. 5a-b).

Comparison of the positive predictive values of both modalities in the assessment of pathologic microcalcifications in relation to the final histologic diagnosis (malignant vs. benign) also shows mammogrpahy to be superior (positive preditive value of 0.88 vs. 0.78 ), which is attributable to the low specificity of ultrasound for microcalcifications ( 0.30 vs. 0.55 ). The results of the $2 \times 2$ tables are summarized in 0 Table 2 .

This superiority is also confirmed by the analysis of agreement between the presence of microcalcifications at ultrasound and the final histologic diagnosis. Here, the kappa value of 0.162 for ultrasound indicates slight agreement versus adequate agreement for mammography (kappa of 0.210).

\section{Discussion}

Mammography screening allows detection of early breast cancer. As a consequence of mammography screening programs, more 

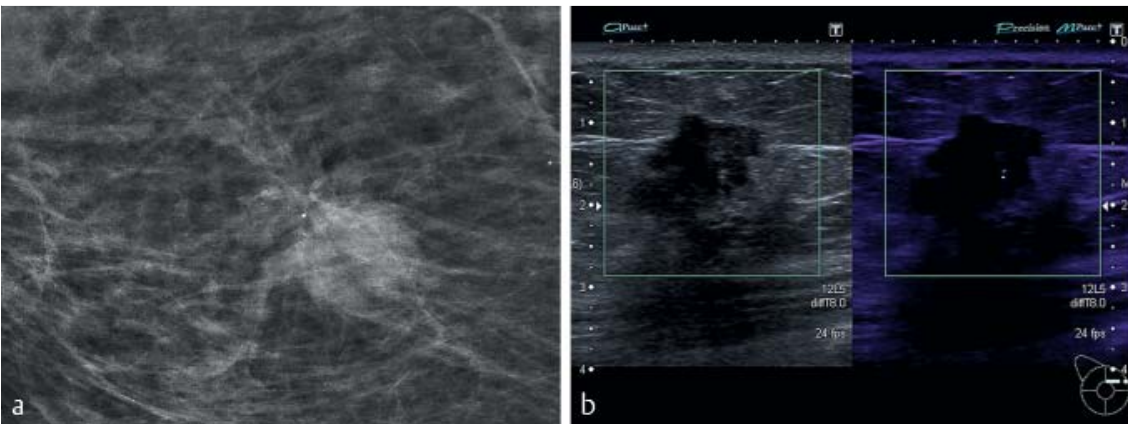

Fig. 2 Mammogram with visible microcalcifications in a focal lesion $(13 \times 20 \mathrm{~mm})$ and adjacent architectural distortion a. Even with optimized presets, the B-mode scan does not reveal the microcalcifications (left). Only the MicroPure technique (right) reveals two microcalcifications within the lesion $\mathbf{b}$. The MicroPure technique enhances not only calcifications within a focal lesion but also artifacts in the vicinity. Therefore, selection of the sensitivity level is a compromise between the detection of microcalcifications and the suppression of artifacts. In this example, the higher sensitivity level (represented by violet) improved the visualization of the calcifications within the focal lesion.
Abb.2 Mammografisch sichtbare Mikroverkalkungen innerhalb eines $13 \times 20 \mathrm{~mm}$ großen Herdes mit angrenzender Architekturstörung a. Die Anwendung eines optimierten Presets erlaubt weiterhin keine Abgrenzung von Mikroverkalkungen im B-Bild (links). Erst durch MicroPure (rechts) sind 2 Mikroverkalkungen im Herd zu visualisieren b. Neben den Verkalkungen im Herd werden auch Artefakte in der Umgebung deutlicher sichtbar, sodass bei der Wahl der Filterstufen ein Kompromiss zwischen den Verkalkungen und Artefakten gefunden werden muss. In diesem Fall waren mit dem empfindlichen Filter Violett die Verkalkungen im Herd besser abzugrenzen.
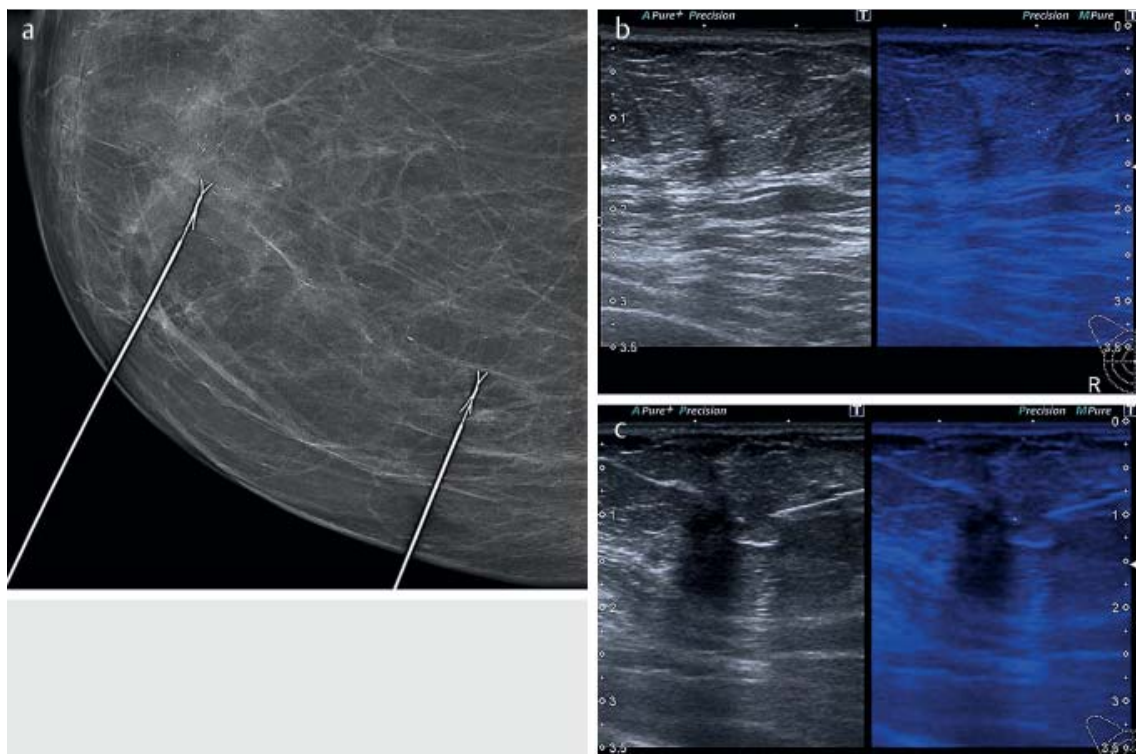

Fig. 3 Mammographic wire placement in a large area of calcification $\mathbf{a}$ in the right upper inner quadrant (histologically proven DCIS with an adjacent radial scar). The use of MicroPure imaging improves the visualization of the diffusely distributed microcalcifications adjacent to a vertically oriented, hypoechoic lesion compared with the B-mode scan on the left $\mathbf{b}$. MicroPure enabled targeted sampling of the microcalcifications $\mathbf{c}$.

Abb.3 Mammografische Drahtmarkierung eines ausgedehnten Verkalkungsareals a im rechten oberen inneren Quadranten (histologisch gesichertes DCIS mit einer benachbarten radiären Narbe). Die Verwendung von MicroPure erlaubt eine bessere Visualisierung von diffus verteilten Mikroverkalkungen angrenzend an die vertikal ausgerichtete echoarme Läsion als im B-Bild auf der linken Bildseite $\mathbf{b}$. Mithilfe von MicroPure wurde die gezielte Biopsie der Mikroverkalkungen möglich c.

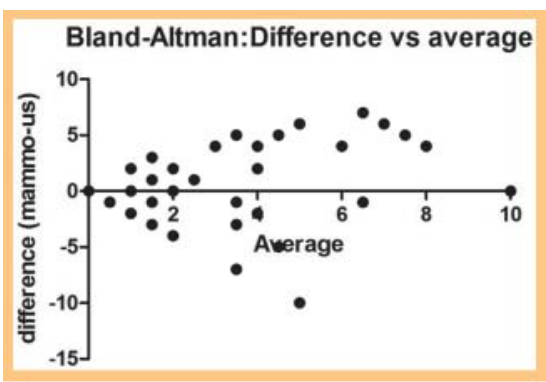

Fig. 4 Bland-Altman plot of the distribution of microcalcifications for mammography and ultrasound (difference versus mean). Bias was $0.43 \pm$ 2.9 (95\% limits of agreement from -5.3 to 6.2 ).

Abb. 4 Verteilung der Mikroverkalkungen im Bland-Altmann-Diagramm für beide Verfahren (Differenz versus Mittelwert). Der Bias betrug 0,43 \pm 2,9 (95\% Limits of Agreement from -5,3 bis 6,2). breast cancers associated with microcalcifications have been detected before they become palpable [21]. As a consequence, there is an increasing need for accurate characterization of suspicious microcalcifications, and efforts have been made to optimize diagnostic tests to improve the detection of microcalcifications in the breast. Mammography is still regarded as the only reliable imaging tool for detecting and classifying microcalcifications $[8,17$, $22-24]$.

In accordance with established guidelines, we used adjunct ultrasound in women with a high proportion of dense glandular breast tissue $(>65 \%$ ) with an ACR density index $\geq 3[17,25,26]$. In the 105 lesions included in the study, white spots suggesting microcalcifications were identified sonographically and these were then additionally examined used MicroPure imaging [11]. For improved visualization of microcalcifications, we used the blue overlay at a sensitivity level of 1 , which was found to yield good results in the visualization of microcalcifications in an earlier in vitro study [3]. Analysis of the 420 stills showed these to be 


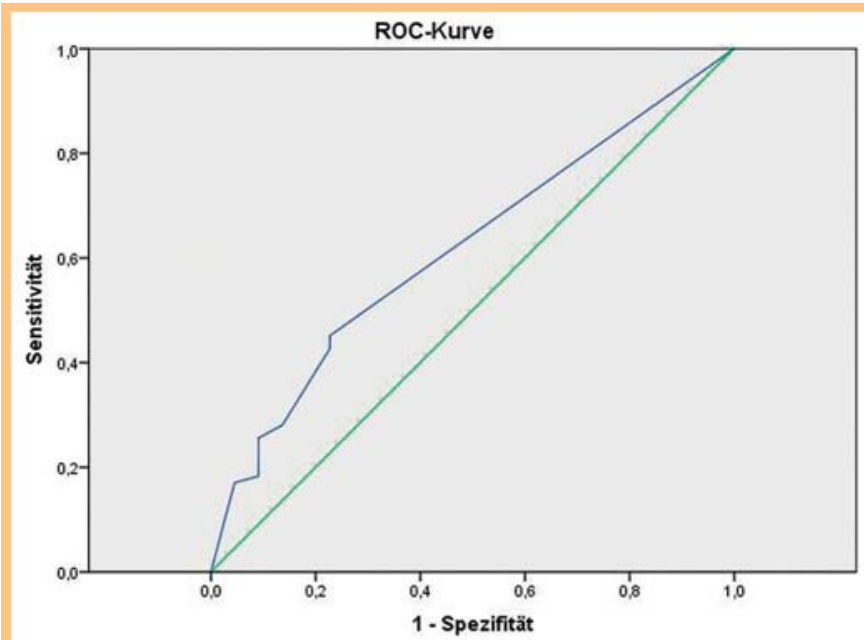

Diagonale Segmente ergeben sich aus Bindungen.

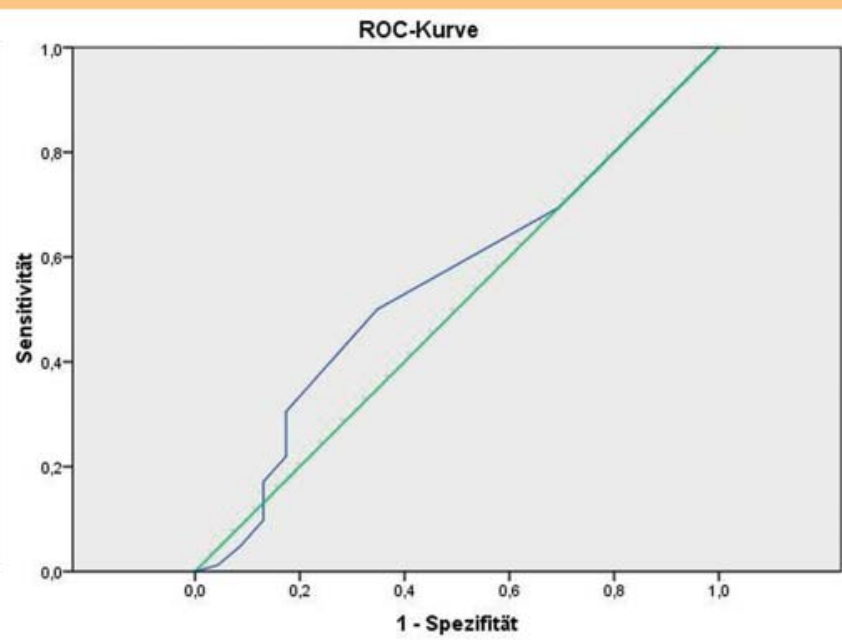

Diagonale Segmente ergeben sich aus Bindungen.

Fig. 5 Area under the curve (AUC) analysis after histologic results were available. This analysis showed the superior detection of microcalcifications by mammography a (AUC $=0.617$, lower limit 0.493 , upper limit 0.741 ) compared with ultrasound $\mathbf{b}$ ( $A U C=0.549$, lower limit 0.418 , upper limit 0.680 ).

Abb.5 Area under the Curve (AUC) Analyse nach Auswertung der Histologie. Hierbei zeigte sich eine Überlegenheit der Mammografie a, (AUC=0,617, Untergrenze 0,493, Obergrenze 0,741) gegenüber der Sonografie $\mathbf{b}$, (AUC=0,549, Untergrenze 0,418, Obergrenze 0,680) in der Mikrokalkdetektion.

markedly inferior to the analysis of video clips, an observation that is consistent with the findings reported by Földi et al. [27]. The average number of microcalcifications detected by ultrasound and mammography did not differ significantly (2.12 vs. 3.59). In 2012, Machado et al. showed that the number of microcalcifications detected sonographically can be improved significantly by using MicroPure imaging compared with gray-scale ultrasound [16]. They concluded that mammography combined with MicroPure markedly improves microcalcification detection compared with mammography plus gray-scale ultrasound examination. Results for mammography alone are not mentioned in the report.

There is good correlation between sonographic and mammographic visualization of microcalcifications. As the threshold of detection, approx. $100 \mu \mathrm{m}$, is the same for MicroPure and grayscale imaging, mammography still detects more microcalcifactions than ultrasound, even with use of the new processing technique. This has been shown in the Bland-Altman plot.

It is well established that malignant microcalcifications are much more conspicuous than benign ones [14, 22, 28]; however, the MicroPure technique cannot differentiate between benign and malignant microcalcifications. This has also been shown by Mansour et al. [29].

The improved detection of microcalcifications by MicroPure imaging compared with conventional gray-scale ultrasound results from how this technique interprets echoes from microcalcifications and surrounding tissue [23].

However, despite the use of MicroPure imaging, mammography still has higher sensitivity and specificity in detecting microcalcifications than ultrasound, as shown by AUC analysis. This is not surprising as mammography visualizes calcifications directly, while ultrasound can detect them only indirectly as the difference in impedance relative to surrounding tissue. Very high spatial resolution is required for microcalcification detection; at the same time, the typical occurrence of microcalcifications in clusters gives rise to the problem of obtaining echoes of identical strength. We must also bear in mind that MicroPure imaging was not developed to replace mammography as the gold standard but rather as an adjunct or a technique to improve microcalcification detection compared with conventional gray-scale ultrasound, especially when ultrasound is used as the initial modality for diagnostic workup.

The main advantage offered by sonographic visualization of microcalcifications is that this capacity allows the use of ultrasound for biopsy guidance. So far, sampling of breast tissue from areas containing microcalcifications has not routinely been done using ultrasound-guided biopsy because the sonographic microcalcification detection rates reported in the literature show very wide variation (from $45 \%$ to $95 \%$ ) $[12,15,28]$. Tissue samples containing microcalcifications yield a more accurate diagnosis than samples that do not [30]. This means that the use of the MicroPure technique would allow more effective diagnosis as it increases the likelihood of sampling tissue that contains microcalcifications. Another advantage of MicroPure is its improved interreader agreement [16]. The combined use of filters and color overlays makes the background more uniform by suppressing the typical pattern of high and low echogenicities of gray-scale ultrasound scans. The color overlay makes it easier to detect microcalcifications even for a less experienced eye. This means that MicroPure imaging can improve microcalcification detection even if breast ultrasound is performed by a less experienced examiner. Some studies have shown a considerable advantage for intraoperative B-mode imaging, even for DCIS [31-33]. And it is well known that the mammographically detected extent of DCIS correlates poorly with the true histologic extent [22]. The additional use of the MicroPure technique in this setting would allow the detection of intraductal microcalcifications, potentially lowering the re-excision rate.

\section{Limitations \\ $\nabla$}

The most serious limitation of MicroPure imaging is its susceptibility to artifacts, resulting in a higher rate of false-positive find- 
ings. Careful evaluation with use of different insonation angles can help reduce artifacts.Our study is limited by the fact that we investigated a highly selected patient population. All patients had palpable breast lesions or microcalcifications that were only detected by sonography. If patients had been selected on the basis of mammography, our analysis would probably have yielded better results for mammography.

Using an upper limit of 10 microcalcifications is another bias in disfavor of mammography; this might explain that there was no difference between ultrasound and mammography in the number of calcifications detected. The use of histology as the standard of reference for comparing ultrasound and mammography is also limited by the fact that histologic processing can lead to the loss of calcifications.

In conclusion, our findings suggest that the MicroPure ultrasound technique is comparable to mammography in terms of diagnostic accuracy. The limitations outlined above are relative. The technique has a potential for enabling songoraphically guided breast biopsies from sites with mammographically detected microcalcifcations and to thus help in reducing false-positive findings. Further studies are necessary and desirable in order to comprehensively evaluate the potential of the MicroPure technique for ultrasound-guided breast biopsy and for elucidating its intraoperative use.

* both authors contributed equally to this manuscript

\section{References}

1 Sickles EA. Mammographic features of 300 consecutive nonpalpable breast cancers. Am J Roentgenol 1986; 146: 661 -663

2 Jackson VP. Diagnostic mammography. Radiol Clin North Am 2004; 42: $853-870$

3 Fischer T, Grigoryev M, Bossenz S et al. Sonographic detection of microcalcifications - potential of new method. Ultraschall in Med 2012; 33: 357-365

4 Mostbeck G. Mammasonografie von Mikrokalk - technisch möglich und klinisch relevant? Ultraschall in Med 2012; 33: 316-319

5 Thomas A, Filimonow S, Slowinski T et al. Steigerung der Bildqualität bei der Dignitätsbeurteilung mammasonografischer Herde mittels Frequenz-Compounding. Ultraschall in Med 2007; 28: 387-393

6 Teh WL, Wilson AR, Evans AJ et al. Ultrasound guided core biopsy of suspicious mammographic calcifications using high frequency and power Doppler ultrasound. Clin Radiol 2000; 55: 390-394

7 Kasumi F. Can microcalcifications located within breast carcinomas be detected by ultrasound imaging? Ultrasound Med Biol 1988; 14: $175-182$

8 Okazaki H, Tsujimoto F, Maeda I et al. Radiologic-pathological correlation of punctate hyperechoic foci by ultrasound in stereotactic vacuum-assisted breast biopsy samples. Jpn J Radiol 2009; 27: 438-443

9 Gufler H, Buitrago-Téllez CH, Madjar H et al. Ultrasound demonstration of mammographically detected microcalcifications. Acta Radiol 2000; 41: $217-221$

10 Madjar H, Ohlinger R, Mundinger A et al. BI-RADS-analogue DEGUM criteria for findings in breast ultrasound-consensus of the DEGUM Committee on Breast Ultrasound. Ultraschall in Med 2006; 27: $374-$ 379

11 American College of Radiology (ACR). Breast Imaging Reporting and Data Systems (BI-RADS ${ }^{\circledR}$ ). Breast Imaging Atlas. Boston, UA: American of Radiology; 2003

12 Balu-Maestro C, Chapellier C, Ben Taaritt I et al. Ultrasound examination of breast microcalcifications: luxury or necessity? J Radiol 2006; 87: $1849-1858$
13 Huang CS, Wu CY, Chu JS et al. Microcalcifications of non-palpable breast lesions detected by ultrasonography: correlation with mammography and histopathology. Ultrasound Obstet Gynecol 1999; 13: 431-436

14 Soo MS, Baker JA, Rosen EL. Sonographic detection and sonographically guided biopsy of breast microcalcifications. Am J Roentgenol 2003; 180: $941-948$

15 Yang WT, Suen M, Ahuja A et al. In vivo demonstration of microcalcification in breast cancer using high resolution ultrasound. Br J Radiol 1997; 70: 685-690

16 Machado P, Eisenbrey JR, Cavanaugh B et al. New image processing technique for evaluating breast microcalcifications: a comparative study. J Ultrasound Med 2012; 31: 885-893

17 Interdisziplinäre S3-Leitlinie für die Diagnostik, Therapie und Nachsorge des Mammakarzinoms; 2012, http://www.awmf.org/uploads/ tx_szleitlinien/032-045OL_k_S3_Brustkrebs_Mammakarzinom_ Diagnostik_Therapie_Nachsorge_2012-07.pdf

18 Kolb TM, Lichy J, Newhouse JH. Comparison of the performance of screening mammography, physical examination, and breast US and evaluation of factors that influence them: an analysis of 27,825 patient evaluations. Radiology 2002; 225: 165-175

19 Sidiropoulos KP, Kostopoulos SA, Glotsos DT et al. Multimodality GPUbased computer-assisted diagnosis of breast cancer using ultrasound and digital mammography images. Int J Comput Assist Radiol Surg 2013; 8: $547-560$

20 Weigel S, Biesheuvel C, Berkemeyer S et al. Digital mammography screening: how many breast cancers are additionally detected by bilateral ultrasound examination during assessment? Eur Radiol 2013; 23: 684-691

21 Katalinic A. Sinkende Mortalität bei steigender Inzidenz beim Mammakarzinom. Geburtsh Frauenheilk 2009; 69: 237-239

22 Kang DK, Jeon GS, Yim H et al. Diagnosis of the intraductal component of invasive breast cancer: assessment with mammography and sonography. J Ultrasound Med 2007; 26: 1587-1600

23 Kamiyama N, Okamura Y, Kakee A et al. Investigation of ultrasound image processing to improve perceptibility of microcalcifications. J Med Ultrasonics 2008; 35: 97-105

$24 \mathrm{Yu}$ PC, Lee YW, Chou FF et al. Clustered microcalcifications of intermediate concern detected on digital mammography: Ultrasound assessment. Breast 2011; 20: 495-500

25 Lenz S. Breast ultrasound in office gynecology-ten years of experience. Ultraschall in Med 2011; 32: S3-S7

26 Madjar H, Sauerbrei $W$, Hansen $L$. Multivariate analysis of flow data in breast lesions and validation in a normal clinical setting. Ultraschall in Med 2011; 32: $511-517$

27 Földi M, Hanjalic-Beck A, Klar M et al. Video sequence compared to conventional freeze image documentation: a way to improve the sonographic assessment of breast lesions? Ultraschall in Med 2011; 32: 497-503

28 Moon WK, Im JG, Koh YH et al. US of mammographically detected clustered microcalcifications. Radiology 2000; 217: 849-854

29 Mansour SM, Adel L. Characterization and guided-procedures of breast suspicious microcalcifications: can MicroPure ultrasound do it? The Egyptian Journal of Radiology and Nuclear Medicine 2012; 43: 499-505

30 Cho N, Moon WK, Cha JH et al. Ultrasound-guided vacuum-assisted biopsy of microcalcifications detected at screening mammography. Acta Radiol 2009; 50: 602-609

31 James TA, Harlow S, Sheehey-Jones J et al. Intraoperative ultrasound versus mammographic needle localization for ductal carcinoma in situ. Ann Surg Oncol 2009; 16: 1164-1169

32 Eichler $C$, Hübbel A, Zarghooni $V$ et al. Intraoperative ultrasound: improved resection rates in breast-conserving surgery. Anticancer Res 2012; 32: $1051-1056$

33 Krekel NM, Haloua MH, Lopes Cardozo AM et al. Intraoperative ultrasound guidance for palpable breast cancer excision (COBALT trial): a multicentre, randomised controlled trial. Lancet Oncol 2013; 14: $48-54$ 